\title{
Flood Wave Propagation in Jingjiang Reach with the Three Gorges
}

\section{Reservoir in Operation}

\author{
Li Chen ${ }^{1, a}$, Haiyun Cheng ${ }^{1, b}$, Yinshan $\mathrm{Xu}^{1, \mathrm{c}}$ \\ Bureau of Hydrology, Changjiang Water Resource Commission, 1863 Jiefang Avenue, Wuhan, \\ Hubei Province, 430010, China

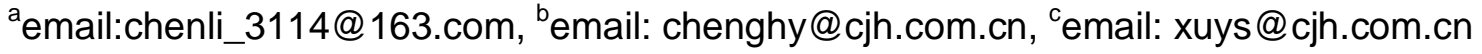

Key words: kinematic wave, surge, celerity, flood travelling time

Abstract: The Jingjiang River is the reach of Yangtze River just downside of the Three Gorges Reservoir (TGR), and most oftenly threatened by the flood. In this reach the natural flood normally routed as kinematic wave, but since TGR put into operation the outflow can be changed dramatically once the controlling valves was opening or closing, and the flood propagates as surge wave in a certain section. As it routed down and being attenuated, the surge gradually transformed into kinematic wave again. The celerity of surge was much faster than that of kinematics, hence the flood travelling time decreased significantly. Accurate prediction of the travelling time is a fundamental factor for effectively controlling flood, and deeper understanding of the flood motion pattern in Jingjiang reach is extremely important. Based on MIKE 11 model built for this reach, scenarios of flood process and propagation time were simulated as accounting for different reservoir regulation strategy. By analysing the results, it was found that the larger the leap to the outflow discharge, and/or the longer time the discharge lasted, a longer section favours for surge propagation and shorter flood routing time.

\section{Introduction}

The Yangtze River is the longest river in China with a length of $6300 \mathrm{~km}$ and a drainage basin of $1.8 \times 10^{6} \mathrm{~km}^{2}$. The annual water discharge is $921 \mathrm{~km}^{3}$ but with a strong seasonal variation, about $70 \%$ of runoff occurs in the flood season from May to October and only $30 \%$ in the rest of the year [1-3]. The frequency of floods in the Yangtze River is high and carrying high costs, the 1998 flood caused more than 200 billion CNY (Chinese currency) in economic losses [4]. The Three Gorges Reservoir was mainly designed to control flooding in the Yangtze River, increasing the flood control ability from a 10-year to a 100-year frequency of flood [5]. Though more than 20 billion $\mathrm{m}^{3}$ of the reservoir storage capacity is created to control flood, TGR cannot solve all the flood problems and flood detention areas are still needed [6]. But the flood diversion regions downstream of TGR are normally reclaimed, cultivated and densely populated, undoubtedly resulting in immense losses once to be used to divert floodwater. The Jingjiang section that just downstream of TGR is in a more critical condition, the plain area along this section is about $40000 \mathrm{~km}^{2}, 15300$ $\mathrm{km}^{2}$ of which is farmed to support a population of 15 million, and the local economy is becoming more and more prosperous $[7,8]$. The dikes in this section were not strong, while in flood season the water level in the river could be $10 \mathrm{~m}$ over the ground surface outside of the bank.

For flood routing in natural channel, the unsteady flow can be varied gradually or rapidly, the latter is characterized by a suddenly changed free surface with high curvature called a surge wave [9, 10]. In Jingjiang reach, the flow of natural floods varied gradually and normally propagated as 
kinematic wave. But since TGR put into operation, the discharge could change dramatically once the controlling valve(s) was opening or closing, caused the flood propagated as surge in a certain reach. As the surge wave routing downstream and being attenuated, it gradually transformed to kinematic wave again. The celerity of surge is much faster than that of kinematic wave, so that the flood travelling time shortened significantly. Accurate prediction of flood wave movement is of vital importance to flood protection and warning [11], in particular the travel time is crucial to Jingjiang reach, where the coincidence of the TGR outflow and the local flow could lead to inundation of the flood diversion district, which obviously will be very costly.

In this paper, the motion of flood wave in Jingjiang was modelled by MIKE 11 in full dynamic wave mode [12]. Scenarios of flooding processes simulated as accounting for different TGR regulation schemes, and the properties of the flood wave were estimated for 3 sections of the upper part of Jingjiang. More effort is made to guarantee reasonable results, including a discussion on a common law of how the different flood waves are transformed.

\section{Methods and Models}

Many effective methods have been used for flood wave propagation [13-17], hydrologic models and hydraulic models are widely used [18-20], but most hydrologic models failed to simulate the channel flows with strong gradients in water depth and velocity. In hydraulic models, for 1D unsteady channel flows the governing equations are the Saint-Venant equations [21]. The propagation of a surge depends on dynamic processes caused by the inclination of the water surface [22-27], while for the positive surge wave advancing downstream, it was similar to that of dam break wave. Chow et al [28] claimed that the full dynamic wave model of Saint-Venant equations could be used for the routing of flash flood due to dam break, and lots of numerical schemes [29-32] have been developed to solve the open-channel flows with surges.

Governing equations. Based on the assumption of hydrostatic pressure distribution and incompressible flows, the Saint-Venant equations for 1D, unsteady open-channel flows can be described:

$$
\frac{\partial E}{\partial t}+\frac{\partial F}{\partial x}=S
$$

In which

$$
E=\left(\begin{array}{l}
A \\
Q
\end{array}\right) ; \quad F=\left(\begin{array}{l}
Q \\
Q^{2} A^{-1}+g I_{1}
\end{array}\right) ; S=\left(\begin{array}{l}
0 \\
g I_{2}+g A\left(S_{0}-S_{f}\right)
\end{array}\right) ;
$$

Where $t$ represents the time; $x$ is horizontal distance along a channel; $A$ is wetted cross-sectional area; $Q$ is volume flow rate; $g$ is gravitational acceleration; $S_{o}$ is bed slope; $S_{f}$ is friction slope; and $I_{1}$ and $I_{2}$ represent the hydrostatic pressure force and the pressure force caused by the longitudinal width variations, respectively. For rectangular, triangular, or trapezoidal cross sections, $I_{1}$ and $I_{2}$ are calculated:

$$
I_{1}=h^{2}\left(\frac{b}{2}+\frac{h S_{L}}{3}\right) ; I_{2}=h^{2}\left(\frac{1}{2} \frac{d b}{d x}+\frac{h}{3} \frac{d S_{L}}{d x}\right) ;
$$

Where $b$ is width of the channel bottom, and $S_{L}$ is side slope (vertical to horizontal) of the channel. In the case of a rectangular non-prismatic channel, $S_{L}$ vanishes and $I_{1}$ and $I_{2}$ are expressed in the following:

$$
I_{1}=\frac{A^{2}}{2 b} ; I_{2}=\frac{A^{2}}{2 b^{2}} \frac{d b}{d x}
$$


Celerity. For the continuous flood wave with gradually varied unsteady flow, the characteristics of both kinematic and dynamic waves can be found simultaneously, but one type is often dominating due to the actual hydraulics and boundaries. Kinematic waves govern flow when inertial and pressure forces are negligible, while dynamical wave govern flow when these force are important.

If the unsteady flow was assumed as superposition of turbulence on a steady flow, the celerity for kinematic and dynamic wave can be calculated as:

$$
\begin{aligned}
& \text { Kinematic Wave: } W_{k}=k u_{0} \\
& \text { Dynamic Wave }: W_{d}=u_{0} \pm \sqrt{g h_{0}}("+": \text { downword, "-": upward })
\end{aligned}
$$

Where $u_{0}, h_{0}$ is the velocity and water depth of early steady flow, $k$ is wave speed coefficient and valued in the range of 1.0 2.0 but determined by the shape of the cross-section. Though some other simplified flood wave models were widely applied, the celerity was similar either to that of kinematic or to that of dynamic. For example, the diffusion wave celerity equals to that of kinematic, while inertia and dynamic wave had a similar celerity, the main difference existed in the ratio of flood wave deformation and attenuation [33].

The motion of flood wave can be sketched as Fig. 1.

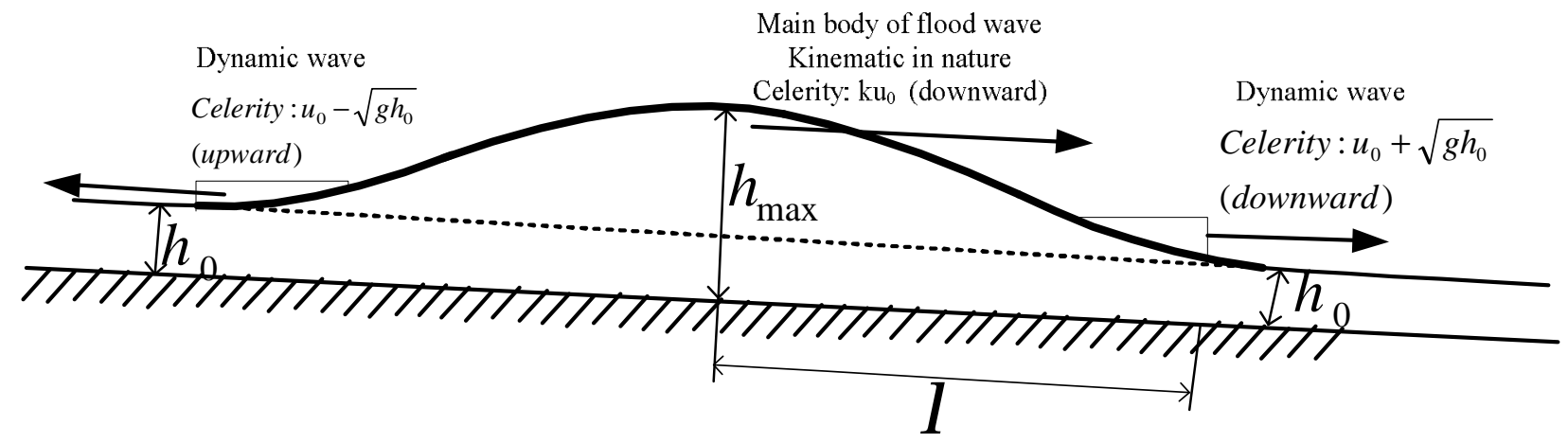

Fig. 1 Motion of continuous flood wave

The decisive factor for a kinematic wave or a dynamic wave can be expressed as [34]:

$$
\begin{aligned}
& \text { Kinematic Wave: } h_{0}<<\lambda S_{0} \\
& \text { Dynamic Wave: } h_{0}>>\lambda S_{0}
\end{aligned}
$$

Normally the celerity of dynamical wave was much faster than that of kinematic wave, but in natural river channel the kinematic wave was often favored, only the reaches with lake character such as the reservoir impounding area, the dynamic wave may dominant the flood propagation.

For surge wave with rapidly varied flow, the celerity for a prismatic channel with a trapezoidal profile can be calculated as [35]:

$$
W_{s}=u_{0}+\sqrt{g\left(\frac{A_{0}}{B^{\prime}}+\frac{3}{2} \zeta+\frac{B^{\prime} \zeta^{2}}{2 A_{0}}\right)}
$$

The derivation of this equation is based on the assumption of an instantaneous discharge jump superposed a steady flow, where $Q_{0}, A_{0}, B_{0}, u_{0}, h_{0}$ are, respectively, the discharge, cross-sectional area, cross width, average flow velocity and water depth of the early steady flow. $A, B, u$ refers to the cross-sectional area, cross width and flow velocity at the moment of peak flow. The hydraulic elements are further illustrated in Fig. 2. 


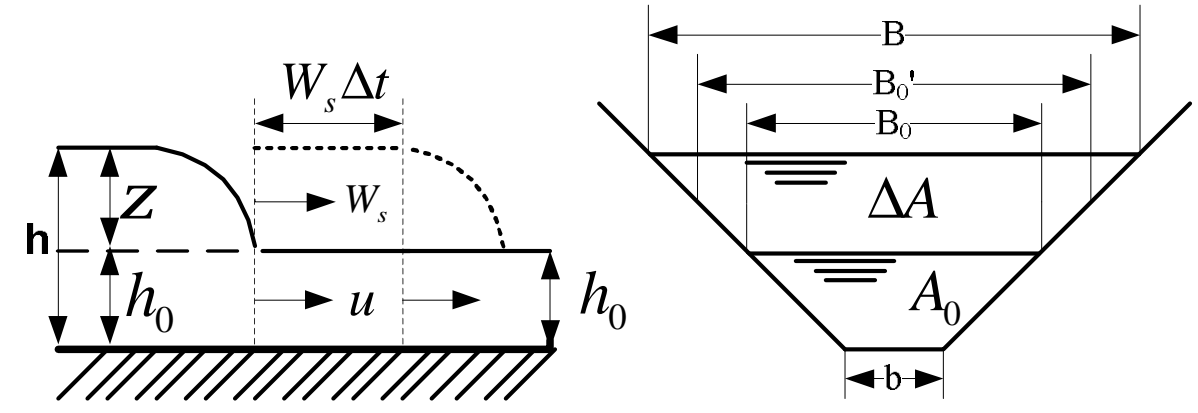

Fig. 2 Delineation of Surge propagation

For a prismatic trapezoidal channel,

$$
\Delta A=\zeta B^{\prime} ; B^{\prime}=\frac{1}{2}\left(B+B_{0}\right)
$$

Where $\zeta$ is the height of the surge, which had a positive value for rising water, and a negative value for returning water. Normally the celerity of a surge is much faster than that of kinematic wave, and becomes even faster with increasing the surge height. For Yichang hydrological station (downstream of TGR dam) in the mainstream of Yangtze River, the flow velocity is about $1.56 \mathrm{~m} / \mathrm{s}$ with a constant discharge of $20000 \mathrm{~m}^{3} / \mathrm{s}$; if the discharge jumps to 35 $000 \mathrm{~m}^{3} / \mathrm{s}$ the surge celerity is $21.3 \mathrm{~m} / \mathrm{s}$; and if discharge jumps to $50000 \mathrm{~m}^{3} / \mathrm{s}$ the surge celerity is up to $24.6 \mathrm{~m} / \mathrm{s}$.

MIKE 11 Model. MIKE 11 developed by Danish Hydraulic Institute (DHI) is one of the most widely used hydraulic models. The core of the model is the hydrodynamic (HD) module, and it provides a choice of 3 different flow descriptions: dynamic wave which uses the full momentum equation including the inertia forces, diffusive wave which only models the bed friction, gravity force and the hydrostatic gradient terms in the momentum equation, and kinematic wave which assumes that the flow is governed by a balance between the friction and gravity forces. The model uses the finite difference approach and a double sweep algorithm to solve the unsteady state flow equations. Based on the hydraulics calculated by the HD module, sediment transport, water quality etc. can be further simulated in a modelled reach.

MIKE11 has been widely used around the world in flood analysis, flood alleviation design, real time flood/drought/water quality forecasting, dam break analysis, optimization of reservoir and river structure operations, sediment transport and ecology and water quality assessments, etc. [36-39]. In China there have also been many successful applications, e.g. in the integrated treatment of Suzhou River in Shanghai, and in evaluation of urban sewage in Chongqing City [40]. Because the model is overcoming the dynamic storage effects in the TGR, it has become a leading tool for daily regulation of the reservoir in the wet season [41].

If the MIKE11 model used the dynamic wave model solving the full momentum equation, the kinematic wave (dynamic) and the surge wave that may appear in Jingjiang could be simulated. Based on 297 cross sections along Jingjiang reach, Markar et al.[42] built up a MIKE 11 model, the error of the simulation is around $0.2 \sim 0.3 \mathrm{~m}$ for water level at the key gauges, and is about $0.2 \mathrm{~m}$ for crest error. With the model parameters and geometric data kept updating, it is still a very important tool for flood forecasting nowadays. 


\section{Shifts of Flood Routing in the Study Area with TGR in operation}

Study area. For the main stream of Yangtze River, the reach just downside of TGR (Yichang) was traditionally called as Jingjiang River, which had a complicated relation between the river and the lake. In the south bank of the reach, three rivers (named as Songzi, Hudu, Ouchi in west to east turn) emanate from Jingjiang, the emanated flow was further divided into a tangled river network and but ultimately jointed to different parts of Dongting Lake. At the same time, the lake receives the runoff from another "Four Rivers" (Xiang, Zi, Yuan and Li). At last the outflow of the lake goes to the Yangtze River at the Chenglingji Station. Also, several tributaries are joining the main stream in this section, among them Qing River is the largest one, but the discharge to Jinjiang was often dominant by the outflow from the TGR. The emanated flow from the 3 ports is measured by 5 hydrological stations (Xinjiangkou, Shadaoguan for Songzi, Mituosi for Taiping, Kangjiagang and Guanjiapu for Ouchi). Qing River, and the four branches of Dongting Lake also had discharge gauges measuring the runoff. The Ouchikou port divided Jingjiang to be the upper- and lower- part, in the upper part there are 2 hydrological stations named as Zhicheng, Shashi, and a water level gauge named as Shishou in turn. Based on these 3 stations, the upper Jingjiang was further divided as Yichang Zhicheng, Zhicheng Shashi and Shashi Shishou, and the length is $64 \mathrm{~km}, 90 \mathrm{~km}, 85$ $\mathrm{km}$ respectively. The river network of the study area is shown in Fig.3.

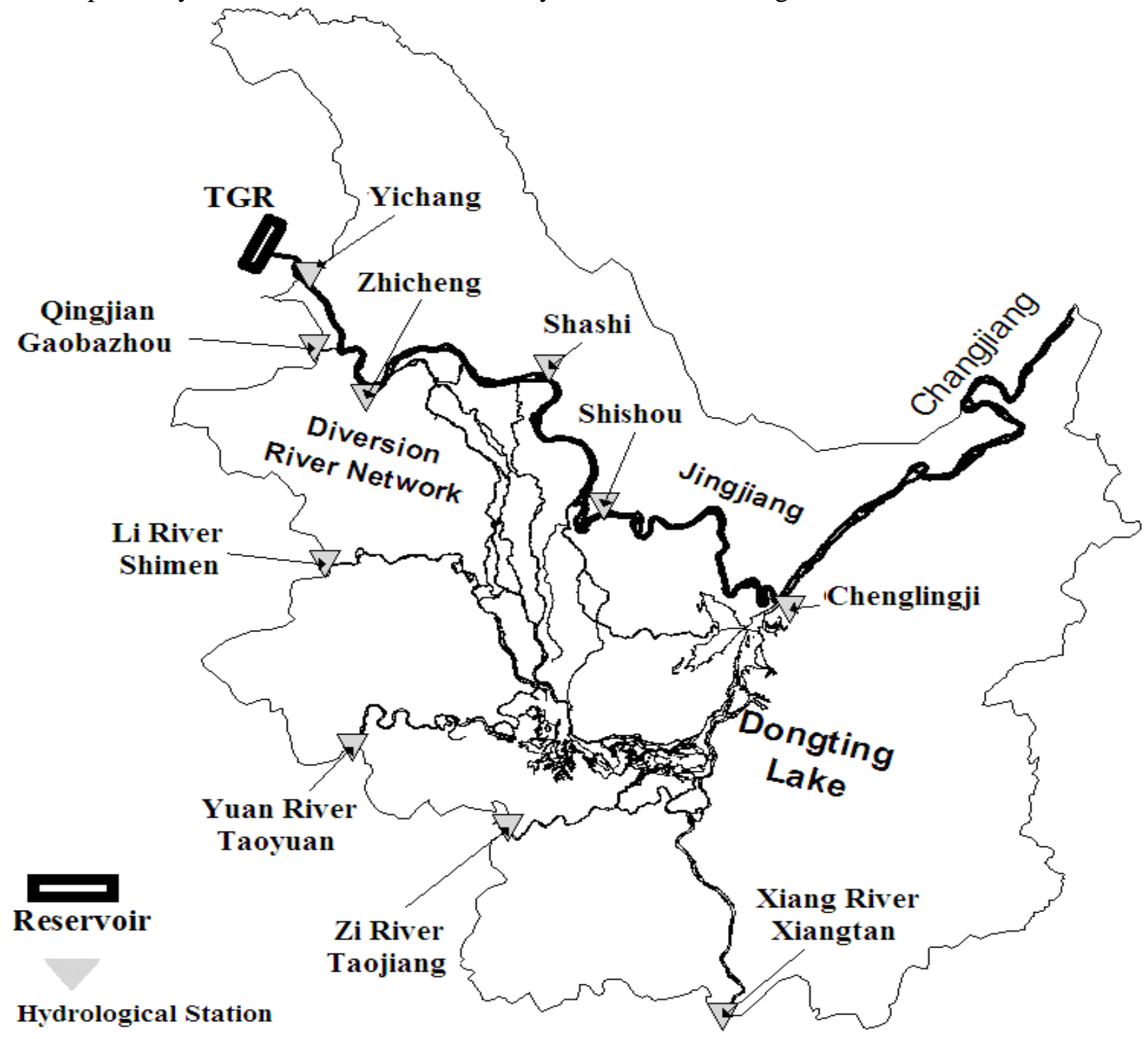

Fig. 3 The Study Area 
Natural Flooding Process and Propagation. As shown in the equations (5) there were several elements affect the flood propagation, for example the period of a flooding process linked to the semi-wave length, longer flooding time would lead to longer wave length and then favouring kinematics. In the upper part of Jingjiang, the natural flood normally lasted more than 10days, e.g. the 1981.08 Flooding (the peak flow exceeded $70000 \mathrm{~m}^{3} / \mathrm{s}$ ) lasted up to 13 days. Even after the first stage of impounding TGR (2003), flooding could last more than 10 days as the reservoir water level was kept constant, e.g. in Sept. 2004 flooding (peakflow exceeded $60000 \mathrm{~m}^{3} / \mathrm{s}$ ) event it lasted about 14 days.

Based on the calibrated MIKE11 model for Jingjiang River, 10-day period flood scenarios with different peakflow (Fig. 4a) were simulated, the celerity is between $u$ and $2 u$ in each of the 3 sections of the upper Jingjiang and equivalent to that of kinematic wave. The propagation time (labelled as $\mathrm{T}_{\mathrm{k}}$ ) for Yichang Zhicheng (Fig. 4b), Zhicheng Shashi (Fig. 4c) and Shashi $\sim$ Shishou (Fig. 4d) shown in Fig. 4 respectively.

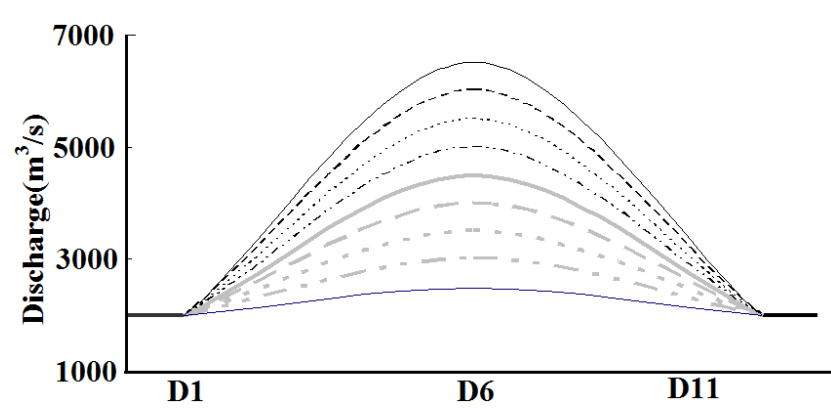

(a)Discharge Scenarios

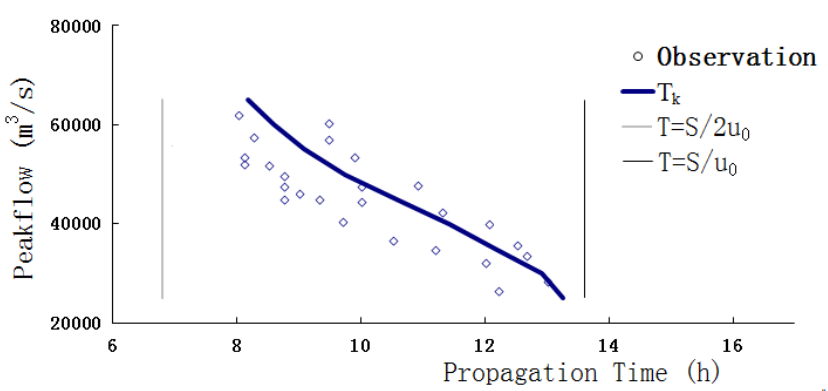

(c) Propagation Time in

Zhicheng Shashi Section

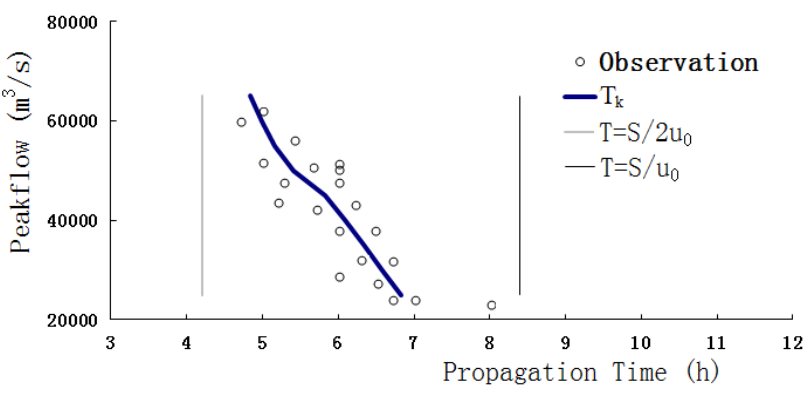

(b) Propagation Time in Yichang Zhicheng Section

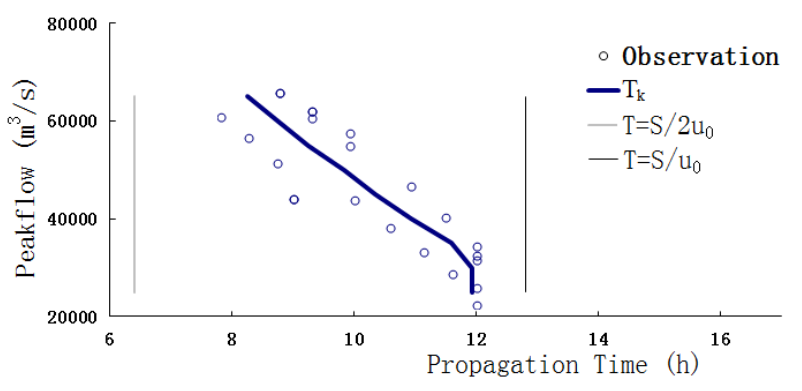

(d) Propagation Time in

Shashi Shishou Section

Fig. 4 Propagation tine of Flood Wave with Different Peakflow in Jiangjiang Reach

The simulated propagation time is close to observations, so that confirming high accuracy of the model. And according to most historical observations, the celerity of natural flood is varied in the range of 1.0 2.0 $u$, so that the natural flood routed as kinematic wave in upper Jingjiang reach.

Shifts to flood routing with TGR in operation. Since the TGR came into operation, the outflow is often changed sharply once the reservoir operated for flood control, i.e. several valves opens instantly. But after the valve operation is completed, the outflow (recognized as discharge at Yichang Gauge) cannot be kept constant but fluctuates in a certain range. The time the maximum water level appears downward is usually not parallel to the time of that at Yichang. One typically example is the flooding process in the early days of Aug. 2009, the discharge at Yichang increased 
rapidly from $25000 \mathrm{~m}^{3} / \mathrm{s}$ to $38000 \mathrm{~m}^{3} / \mathrm{s}$, but the discharge shows an oscillation in the following 6 days with peak flow $40200 \mathrm{~m}^{3} / \mathrm{s}$. The time that the crest water level $\left(T_{a}\right)$ appeared was 5th 14:00 pm, 5th 17:45 pm, 7th 2:00 am and 10th 14:00 pm at Yichang, Zhicheng, Shashi and Shishou, respectively. The crest water level at Shashi and Shishou was by no means corresponding to the maximum discharge at Yichang. But if one takes a close look at the returning process, once the valves in TGR started to close, the time that the water level starts to decrease $\left(T_{b}\right)$ in these gauge shows a good correspondence. Fig. 5 shows this flooding process.

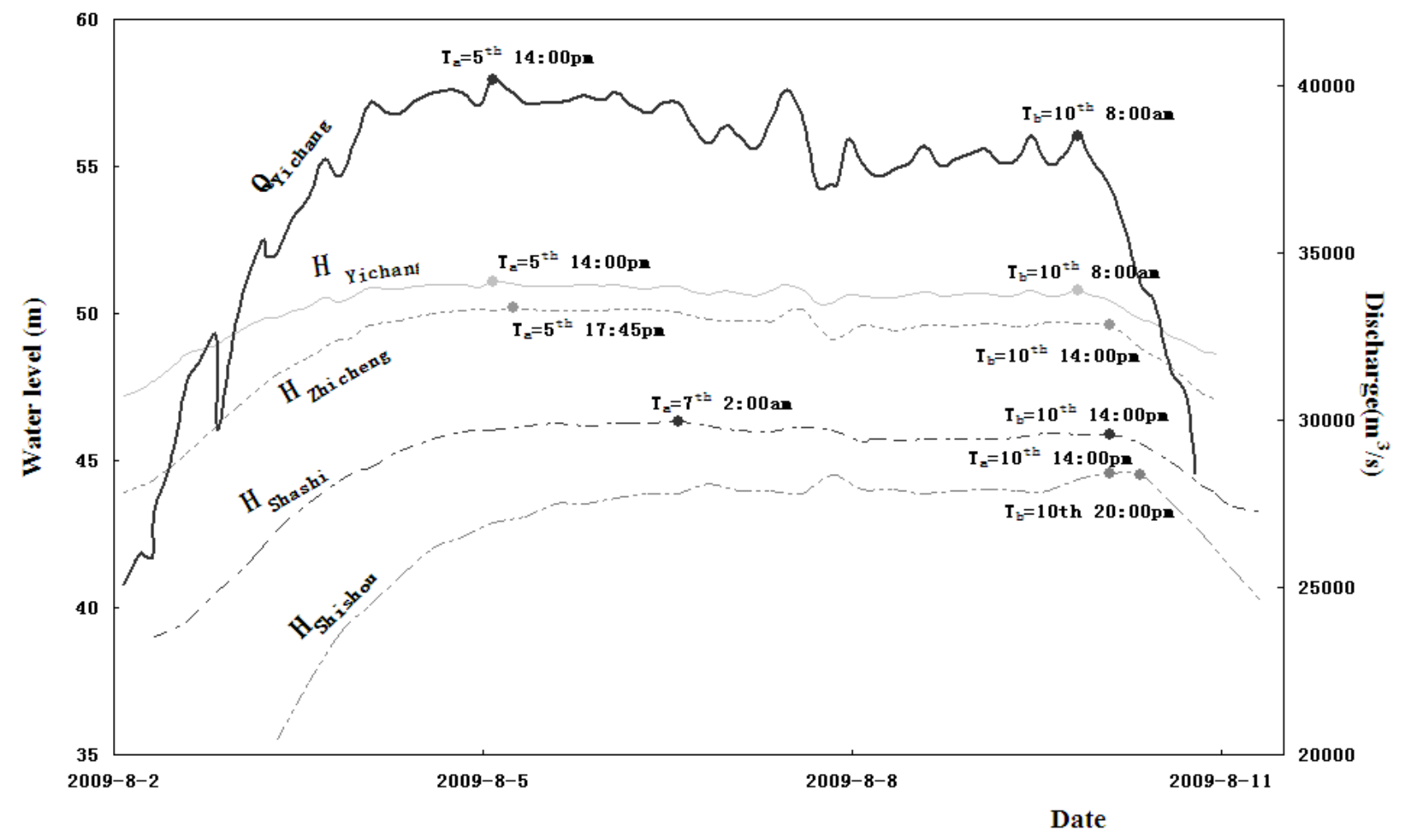

Fig. 5 Flood Process in Jingjiang Reach in early August 2009

If $T_{b}$ is used to estimate the propagation time in Jingjiang Reach, and in combination with many other samples of flooding released from the TGR in recent years, the estimations are about $3 \mathrm{~h}$, $6 \mathrm{~h}$ and $6 \mathrm{~h}$ for the parts of Yichang Zhicheng, Zhicheng Shashi and Shashi Shishou section, but that may change with different TGR regulation schemes.

\section{Effects on Flood Routing With Different TGR regulation Scheme}

Based on equation (6), the surge celerity is impacted by several hydraulic parameters. On this project it is analysed how the flood propagates with different margins of the discharge leap and the different periods the discharge leap lasts. The pre-condition of the flood in this section is assumed as: the discharge of the steady flow in early stage is $20000 \mathrm{~m}^{3} / \mathrm{s}$, and the jump of discharge lasts in 6 hours and changes evenly.

Effects of Surge Discharge on the Flood Routing. For the flood scenarios (Fig. 6a) it is assumed that the changed discharge will last for 5 days, and that the discharge will jump to $25000 \mathrm{~m}^{3} / \mathrm{s}, 30$ $000 \mathrm{~m}^{3} / \mathrm{s}, 35000 \mathrm{~m}^{3} / \mathrm{s}, 40000 \mathrm{~m}^{3} / \mathrm{s}, 45000 \mathrm{~m}^{3} / \mathrm{s}, 50000 \mathrm{~m}^{3} / \mathrm{s}, 55000 \mathrm{~m}^{3} / \mathrm{s}, 60000 \mathrm{~m}^{3} / \mathrm{s}$ and 65000 $\mathrm{m}^{3} / \mathrm{s}$, respectively, to analyse how the changed discharge impacts surge propagation. The flood propagation time in Yichang Zhicheng (Fig. 6b), Zhicheng Shashi (Fig. 6c), and Shashi Shishou (Fig. 6d) was simulated and compared to $T_{k}$ (simulation in Fig. 4) and $T_{s}\left(T_{s}=S / W_{s}, W_{s}\right.$ computed by 
equation 6 and averaged for these 3 reaches), as shown in the Fig. 6.
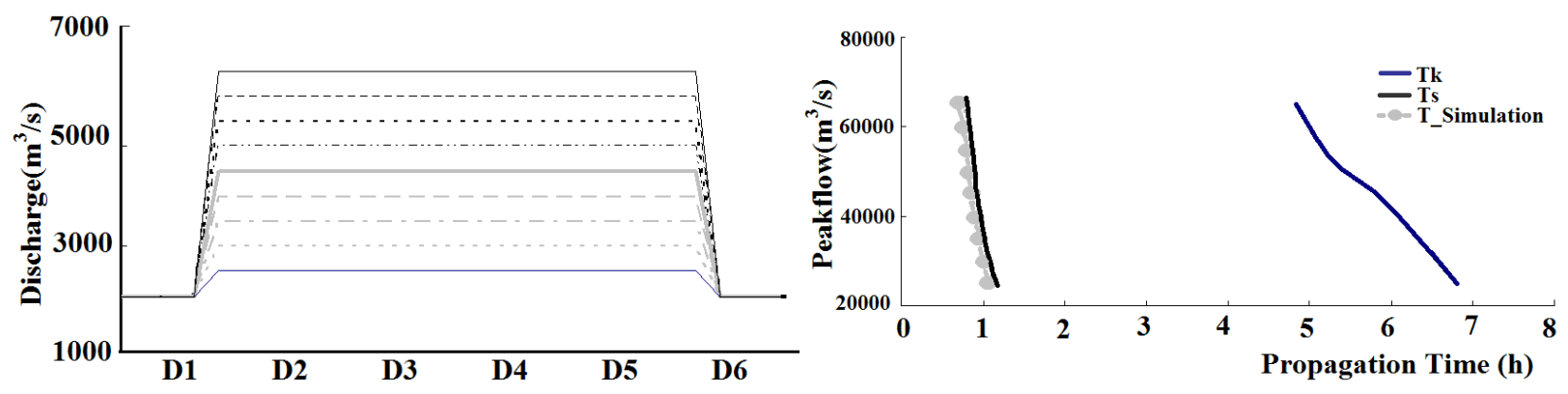

(a) Discharge Scenarios

(b) Propagation Time in Yichang Zhicheng Section

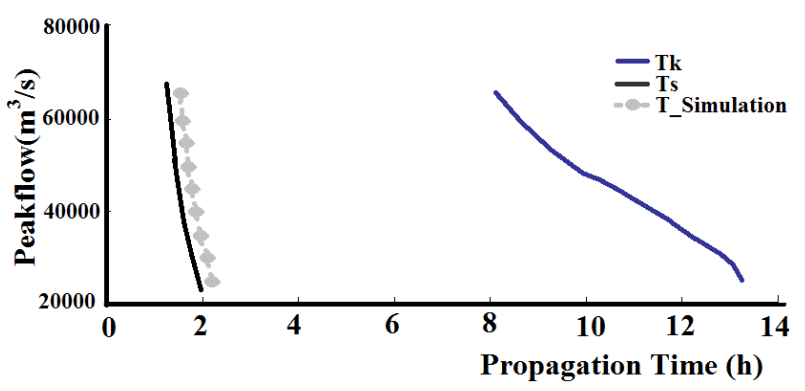

(c) Propagation Time

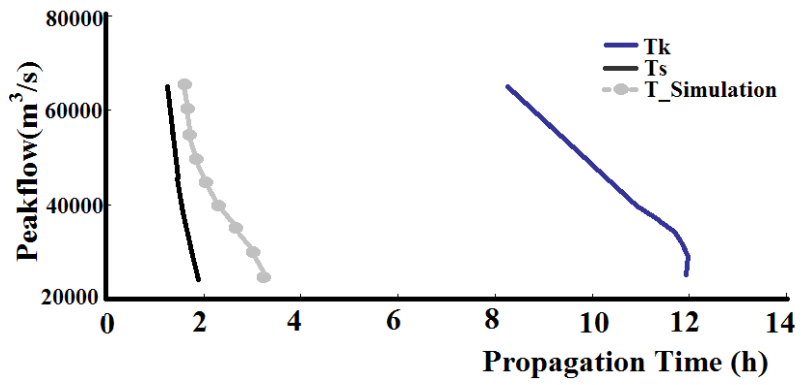

(d) Propagation Time

in Zhicheng Shashi Section

in Shashi Shishou Section

Fig. 6 Propagation Time in Upper Jingjiang Reach with Different Changed Discharge

From Fig. 6 one can see that in the sections of Yichang Zhicheng and Zhicheng Shashi, the flood almost propagates in the mode of a surge, while in Shashi Shishou section it appears as surge only when the discharge is increased to $45000 \mathrm{~m}^{3} / \mathrm{s}$ or larger, otherwise only a part favours surge while the other part may propagate as a kinematic wave. The smaller the change of the discharge, the longer length could be fit to a kinematic wave. The conclusion is that the larger surge discharge, the longer distance the wave propagates as a surge.

Effects of Surge Lasting Time on the Flood Routing. Then the flood scenarios (Fig. 7a) were set to a $45000 \mathrm{~m}^{3} / \mathrm{s}$ surge flow lasting 1,2,3, 4, and 5 days, respectively, to analyse how the lasting time of the surge discharge impacts the surge propagation. The flood propagation time in Yichang Zhicheng (Fig. 7b), Zhicheng Shashi (Fig. 7c) and Shashi $\sim$ Shishou (Fig. 7d) was simulated and compared with $T_{k}$ (simulation in Fig. 8 for a $45000 \mathrm{~m}^{3} / \mathrm{s}$ peak flow flood) and $T_{s}$, as shown in Fig. 7. 

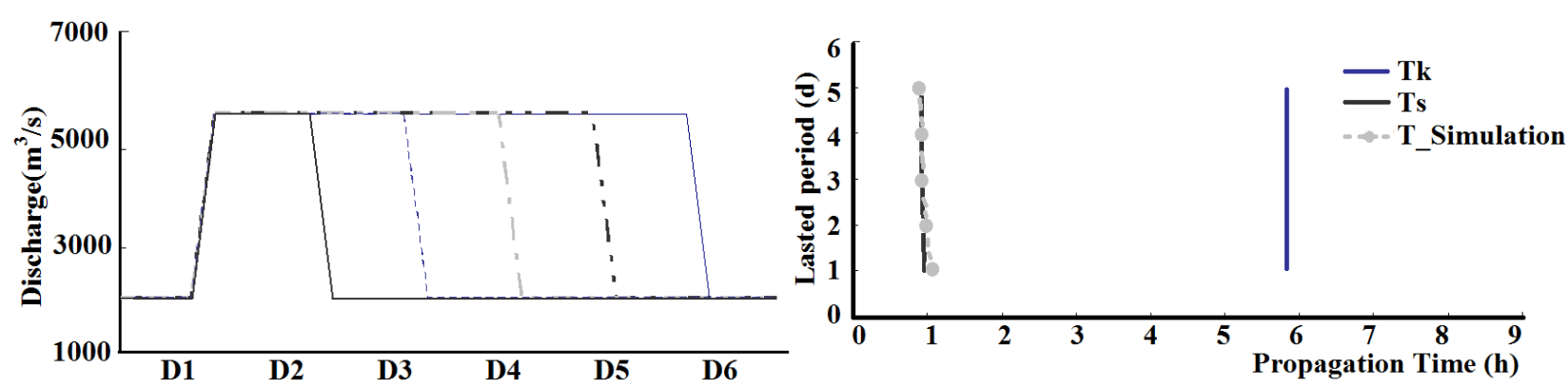

(a) Discharge Scenarios

(b) Propagation Time in Yichang Zhicheng Section

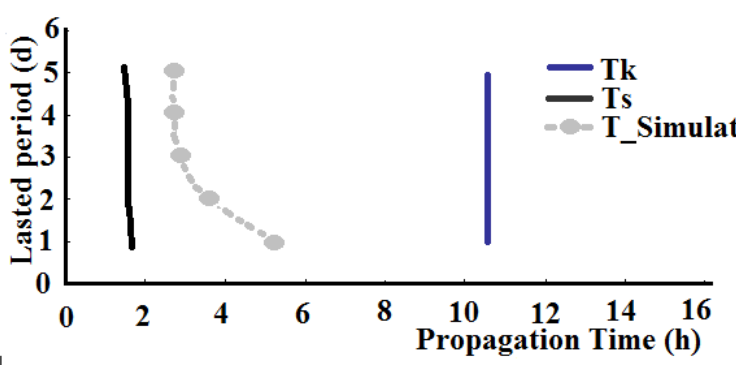

(c) Propagation Time in

Zhicheng Shashi Section

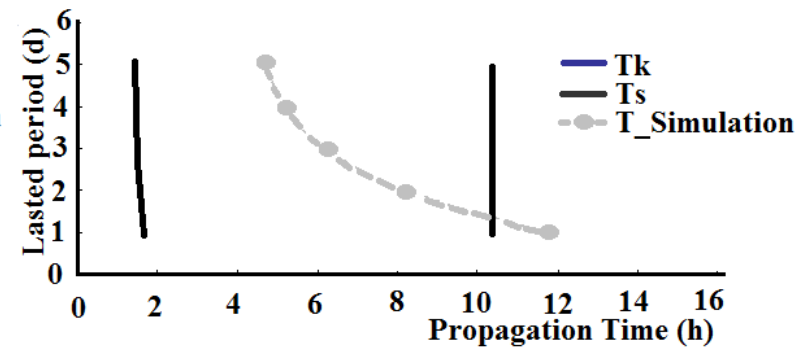

(d) Propagation Time in

Shashi Shishou Section

Fig. 7 Propagation Time in Upper Jingjiang Reach with Different Lasted Time of the large

Discharge

From Fig. 7 it can be seen that: in Yichang Zhicheng section the flood propagates in the mode of surge; in Zhicheng Shashi section the flood almost propagates as surge when the large discharge lasted more than 3 days, but if shorter than 3 days part of the section flood propagates in kinematic wave mode. In Shashi Shishou section, if the lasting time is less than 2 days, the flood propagates almost in a kinematic manner, if it lasts longer some part may be a surge, and the other part may be kinematic. The outcome is that longer flooding times and longer distances in the upper reach favour surge propagation.

Discussion. The surge can be recognized as a series of elementary waves with infinite intervals, the larger discharge the larger the energy contained and the larger the celerity. The energy of the elementary wave will be continuously depleting as it propagates along the channel. After a certain distance of elementary wave propagation, the difference of energy between the elementary waves will be reduced to the range of a kinematic wave, so the surge is gradually transited to a kinematic wave.

The larger the surge discharge, the larger the energy difference between the original and the final elementary wave will be, and a longer distance is needed to reduce the difference. Moreover, the longer time the surge discharge lasts, the larger is the total energy difference between the surge elementary, and a longer distance is needed to reduce the difference. That is the reason why in case of larger surge discharges and longer lasting surges, the longer the length that favours the surge mode. 


\section{Conclusion}

In this paper, based on an early calibrated MIKE 11 model for Jiangjiang Reach, the flood propagation time in the upper part were simulated under different boundary conditions as accounting different TGR regulation strategy, the main conclusions include: (1) In the upper Jingjiang Reach the natural flood fits a kinematic wave, but since the TGR is used for flood control, the flood is transited from a surge to a kinematic wave; (2) the larger the surge discharge and the longer the time of outflow from the TGR, the longer the length of surge mode in the upper part of Jingjiang Reach.

\section{Acknowledgments}

The study is financially supported by the National Non-Profit Research Program of China (Grant No. 201201054).

\section{Reference}

[1] K. Chau, C. Wu and Y. Li: Comparison of Several Flood Forecasting Models in Yangtze River. J. Hydrol. Eng. Vol. 10-6 (2005), p. 485-491.

[2] Y. Ding, Y. Jia and S. Wang: Three-Dimensional Numerical Simulation of Tidal Flows in the Yangtze River Estuary. World Environmental and Water Resources Congress (2011), p. 2135-2144.

[3] Q. Ju, Z. Yu, Z. Hao, G. Ou, Z. Wu, C. Yang and H. Gu: Response of Hydrologic Processes to Future Climate Changes in the Yangtze River Basin. J. Hydrol. Eng. Vol. 19-1 (2014), p. 211-222.

[4] G. Zeng and X. Kong: Preliminary study on the causes and countermeasures of the 1954 and 1998 extraordinary Yangtze River flood. J. Catastrophol. Vol. 14-4 (1999), p. 22-26 (in Chinese).

[5] Q. F. Zhang and Z. P. Lou: The environmental changes and mitigation actions in the Three Gorges Reservoir region, China. Environ. Sci. Policy. Vol. 14(2011), p. 1132-1138.

[6] H.W. Fang, D. Han, G. J. He and M. H. Chen, , Flood management selections for the Yangtze River midstream after the Three Gorges Project operation, J. Hydrol. Vol. 432-433(2012), p. $1-11$.

[7]F. Yuan and T. Jiang: Land use dynamical analysis on the Jingjiang flood diversion district, Yangtze River, Resource and Environment in the Yangtze Basin Vol. 14-5 (2005), p. 649-654 (in Chinese).

[8]S. Hayashi, S. Murakami, K. Q. Xu and M. Watanabe: Effect of the Three Gorges Dam Project on flood control in the Dongting Lake area, China, in a 1998-type flood. J. Hydro-Envir Res. Vol. 2-3 (2008), p. 148-163.

[9] H. Favre: Etude théorique et expérimentale des ondes de translation dans les canaux découverts, Dunod, Paris (1935).

[10] V. T. Chow: Open-channel hydraulics, McGraw-Hill, New York (1959).

[11] P. Wormleaton, andM. Karmegam: Parameter Optimization in Flood Routing. Vol. J. Hydraul. Eng. Vol. 12(1984), p. 1799-1814.

[12] DHI: A Modelling System for Rivers and Channels: Reference Manual. Danish Hydraulic Institute, Hørsholm, Denmark(2004).

[13] Y. Huang: Appropriate Modeling for Integrated Flood Risk Assessment. Ph. D. Dissertation. Enschede: The University of Twente (2005). 
[14] L. Begnudelli and B. F. Sanders: Simulation of the St. Francis dam-break flood. J. Eng. Mech. Vol. 133-11 (2007), p. 1200-1212.

[15] S. S. Chen, Q. M. Zhong and J. J. Tao: Development in embankment dam break simulation and water flow simulation. Adv. Water Sci, Vol. 19-6 (2008), p. 903-910. (in Chinese)

[16] D. Viviroli, H. Mittelbach, J. Gurtz and R. Weingartner: Continuous simulation for flood estimation in ungauged mesoscale catchments of Switzerland, Part II: Parameter regionalisation and flood estimation results. J. Hydrol. Vol. 377-1,2 (2009), p. 208-225.

[17] F. Dottori and E. Todini: Developments of a flood inundation model based on the cellular automaton approach: Testing different methods to improve model performance. Physics and Chemistry of the Earth, Parts A/B/C, Vol.36 -7,8 (2011), p. 266-280.

[18] R. Price: Volume-Conservative Nonlinear Flood Routing. J. Hydraul. Eng. Vol.135-10 (2009), p. 838-845.

[19] B. Reza, R. Sajjad and H. A. Gholam: Analysis of dynamic wave model for flood routing in natural rivers, Water Sci. Eng. Vol. 5-3(2012), p. 243-258.

[20] X. Cai, Y. Li, X.W. Guo and W. Wu: Mathematical model for flood routing based on cellular automaton. Water Sci. Eng. Vol. 7-2 (2014), p. 133-142.

[21] B. de St. Venant: Theorie du mouvement non-permanent des eaux avec application aux crues des rivers et a introduction des mares dans leur lit. Acad. Sci. Comptes Redus, Paris, Vol. 73,99(1871), p. 148-154 , p.240-273 (in French)

[22] J.Faure and N. Nahas: Etude numérique et experimental d'intumescences à forte courbure du front. La Houille Blanche, 5 (1961), p. 576-587.

[23] F. Benet and J. A. Cunge: Analysis of experiments on secondary undulations caused by surge waves in trapezoidal channels. J. Hydraul. Res. Vol. 9-1 (1971), p.11-33.

[24] K. I. Zairov and P. P. Listrovoy: Experimental investigation of the positive traveling surges fore-part observed in canals. Proc., 20th International Association for Hydraulic Research (IAHR) Congress (1983), P. 210-218.

[25] A. Treske: Undular bores (Favre-waves) in open channels Experimental studies. J. Hydraul. Res. Vol. 32-3 (1994), p. 355-370.

[26] F. S. Soares and Y. Zech: Undular bores and secondary waves-Experiments and hybrid finite-volume modelling. J. Hydraul. Res. Vol. 40-1 (2002), p. 33-43.

[27] T. Meile, J. L. Boillat and A. J. Schleiss: Propagation of surge waves in channels with large-scale bank roughness. J. Hydraul. Res. Vol. 51-2 (2013), p. 195-202.

[28] V. T. Chow, D. R. Maidment and L. W. Mays: Applied Hydrology. McGraw-Hill Book Company, Singapore (1988), p. 330-331.

[29] M. Nujic: Efficient implementation of non-oscillatory schemes for the computation of free-surface flows. J. Hydr. Res., Delft, The Netherlands, Vol. 33-1 (1995), p. 101-111.

[30] A. K. Jha, J. Akiyama and M. Ura: A fully conservative Beam and Warming scheme for transient open channel flows. J. Hydr. Res.,Delft, The Netherlands, Vol. 34(5) (1996), p. 605-621.

[31] M. Jin and D. L. Fread: Dynamic flood routing with explicit and implicit numerical solution schemes. J. Hydr. Engrg. Vol. 123-3 (1997), p. 166-173.

[32] E. A. Meselhe, F. Sotiropoulos and F. M. Jr. Holly: Numerical simulation of transcritical flow in open channels. J. Hydr. Eng. Vol. 123-9 (1997), p. 774-783.

[33] J.Z Li and S Z. Ye: Analysis about dynamical characteristic of flood waves in the reservoir region after the completion of the Three-Gorge Project., J. Hydroel. Eng., Vol. 9-4 (1991), p. 265-273, (in Chinese) 
[34] Z. F. Xu: Discussion of flood wave transition in reservoir area. Yangtze River, Vol. 9(1987), p. 14-20, (in Chinese)

[35] J.X. Li: Hydraulics, Hohai University Press. China (1996), p. 358-365.

[36] J. R. Thompson, H. R. Sørenson, H. Gavin and A. Refsgaard: Application of the coupled MIKE SHE/MIKE 11 modelling system to a lowland wet grassland in southeast England. J.Hydrol. Vol. 293 (2004), p. 151-179.

[37] H.L. Liu, X.i Chen, A.M. Bao and L Wang: Investigation of groundwater response to overland flow and topography using a coupled MIKE SHE/MIKE 11 modeling system for an arid watershed. J.Hydrol. Vol. 347(2007), p. 448-459.

[38] K. P. Rabindra, P. Niranjan and B. Biplab: Simulation of river stage using artificial neural network and MIKE 11 hydrodynamic model”, Comp. Geosci. Vol. 36-6 (2010), p. 735-745.

[39] D. Charalampos, G. Pantazis, P.Dimitris and P.Dimitris: Ecosystem approach to water resources management using the MIKE 11 modeling system in the Strymonas River and Lake Kerkini. J. Environ Manag. Vol. 94-1 (2012), p.132-143.

[40] L.Y. Wang: Denmark MIKE11 hydrodynamic module in the application of river network simulation research. China Water Transp. Vol. 02 (2007), p.106-107 (in Chinese).

[41] Y.W. Min , J. Wang and L. Chen: Discussion on calculation method of flood routing and inflow of Three Gorges Reservoir. Yangtze River., Vol. 42-6 (2011), p. 49-52. (in Chinese).

[42] M.S. Markar, S.Q. Clark, Y.W. Min, F.W. Zhang and H.M. Zhou: New flood forecasting system of Yangtze River in China. Proceedings of the Second international Yellow River Forum (2005), (In Chinese). 